\title{
Implicancias del cambio \\ de la política agrícola de los Estados Unidos
}

\section{Carlos Basco}

Consultor independiente

\section{Iván Buccellato}

Investigador asistente

\section{Valentina Delich}

Investigadora

\section{Diana Tussie}

Investigadora

FLACSO- Red Latinoamericana de Política Comercial
Este artículo busca presentar los aspectos principales de la nueva legislación agrícola de los Estados Unidos, su grado de conformidad con las disposiciones de la Organización Mundial del Comercio (OMC) y una estimación preliminar sobre su impacto en América Latina. En él se examina en primer lugar la nueva Ley de Seguridad Agrícola y de Inversión Rural de 2002 de los Estados Unidos, desglosando los distintos mecanismos de apoyo a los productores agrícolas de ese país. En seguida se analiza dicha ley, a la que en adelante nos referiremos como Ley Agrícola 2002, a la luz de las normas establecidas y los compromisos asumidos en la Ronda Uruguay del Acuerdo General sobre Aranceles Aduaneros y Comercio (GATT). Luego se evalúa el posible impacto de esta nueva ley en la agricultura de los países latinoamericanos. Y, por último, se hace referencia a acontecimientos recientes en las negociaciones comerciales multilaterales y su relación con la Ley Agrícola 2002. 


\section{Introducción}

La Quinta Conferencia Ministerial de la omc (Cancún, México, 10 a 14 de septiembre de 2003), realizada en el marco de la Ronda de Negociaciones Multilaterales de Doha actualmente en marcha, puso en evidencia las intenciones de la Ley Agrícola $2002^{1}$ de los Estados Unidos y mostró que ese país está dispuesto a legitimar su arsenal de subsidios en la ronda actual. En Cancún las negociaciones comerciales multilaterales colapsaron por falta de acuerdo en los temas agrícolas, a raíz de la defensa de las estructuras proteccionistas efectuada por los países desarrollados. Con la Ley Agrícola 2002, Estados Unidos marcó un brusco viraje, pasando del campo de la liberalización al campo del proteccionismo.

La principal característica del régimen de subsidios de la Ley Agrícola 2002 es su carácter contracíclico, que tiene como efecto la sobreproducción de productos básicos. Esto deprime los precios y conduce a una suerte de sobrecolocación de estos productos en el mercado mundial. Sin embargo, la implementación de esta ley tiene consecuencias que van más allá de la continuación de los programas de apoyo a los agricultores. Debido a que actualiza la superficie y los rendimientos en que se basan los cálculos de los programas de apoyo, la nueva normativa cambia la naturaleza de los pagos directos que otorga el gobierno, de "desconectados" a "reconectados". ${ }^{2}$ Esto constituye un retroceso respecto de los tímidos avances de la Ronda Uruguay.

Se estima que el gasto anual de Estados Unidos en productos básicos alcanzará entre 15.000 y 20.000 millones de dólares sólo para los cultivos, lo que re- presenta un aumento de entre $70 \%$ y $80 \%$ con respecto a lo estipulado por la Ley Federal de 1996 de Reformas y Mejoras a la Agricultura (a la que en adelante llamaremos Ley Agrícola 1996) en su último año de vigencia. El presupuesto total de la Ley Agrícola 2002 ha sido estimado en 180.000 millones de dólares para el período total de implementación (seis años). Por ello, es probable que los Estados Unidos sobrepase el límite consolidado en la OMC para la Medida Global de la Ayuda (MGA), de 19.100 millones de dólares por año.

Más allá de sus diferencias, la política agrícola de los Estados Unidos y la Política Agrícola Común (PAC) de la Unión Europea buscan crear redes de protección capaces de promocionar y subsidiar a sus productores en sectores sofisticados y de mayor valor agregado. ${ }^{3}$ Es por esto que los aumentos de los subsidios por uno de estos dos actores globales, y la consiguiente reacción del otro, resultan sumamente perjudiciales para los países latinoamericanos que producen bienes agrícolas. En tales circunstancias, es evidente que los países en desarrollo no actúan en un campo de juego parejo.

La cuestión asume vital importancia, ya que entre los reducidos medios con que cuentan los países en desarrollo, para contrarrestar las medidas proteccionistas de las grandes potencias, se encuentra su propia capacidad de establecer reglas que les favorezcan en las negociaciones comerciales que se llevan a cabo en el marco de la омc. En este sentido, la Ley Agrícola 2002 puede ser vista como un elemento estratégico para alterar los compromisos asumidos y cambiar las reglas de juego en las negociaciones en curso.

\footnotetext{
${ }^{1}$ Farm Security and Rural Investment Act of 2002, conocida también como Farm Bill 2002.

${ }^{2}$ La clasificación de pagos conectados y desconectados se relaciona con los efectos sobre la producción que pueden tener estos subsidios. Si los pagos están asociados al volumen de producción, se considera que están "conectados", ya que existe una relación directa entre los montos desembolsados y los niveles de producción. En caso contrario, si los pagos se realizan sin afectar el volumen de producción, se considera que son "desconectados".
}

\footnotetext{
${ }^{3}$ El valor de la producción a la salida de la granja de los sectores agrícolas de Estados Unidos y la Unión Europea es casi el mismo: alrededor de 190.000 millones de dólares por año (OCDE, 2001). El principal indicador de la Organización de Cooperación y Desarrollo Económicos (OCDE) respecto al apoyo interno (Total Support Estimate, TSE) muestra que en 2000 Estados Unidos destinaba 92.300 millones de dólares anuales al apoyo de la agricultura, mientras que la Unión Europea dedicaba 10.500 millones de dólares al mismo fin. Sin embargo, la distribución per cápita de los montos indica que los granjeros estadounidenses reciben aproximadamente 338 dólares per cápita por año, mientras que los de la Unión Europea perciben 276 (Unión Europea, 2002).
} 


\section{II}

\section{La Ley de Seguridad Agrícola y de Inversión Rural de Estados Unidos (P.L. 107-171)}

Esta ley, que en el presente artículo denominamos Ley Agrícola 2002, regula los desembolsos que va a hacer el gobierno estadounidense para apoyar a sus productores agrícolas en el período 2002-2007, indicando montos y condiciones de acceso a los distintos programas. Los tres primeros capítulos de la ley (I. Programas de productos básicos; II. Conservación, y III. Comercialización) constituyen el núcleo central de los programas de apoyo a los agricultores estadounidenses que tendrán mayor impacto en la actividad agrícola de los países de América Latina: programas de pagos directos, de pagos contracíclicos, de préstamos de asistencia a la comercialización y de pagos $\operatorname{LDP}^{4}$ en reemplazo de tales préstamos, programas de conservación y programas de apoyo a las exportaciones.

\section{Programas de productos básicos}

Los productos considerados como básicos en la Ley Agrícola 2002 son: trigo, maíz, sorgo, avena, cebada, algodón de altura, arroz, y soja y otras oleaginosas. ${ }^{5}$ Los subsidios a los ingresos de los productores de bienes básicos se otorgan principalmente a través del programa de pagos directos, del programa de pagos contracíclicos y de diversos programas relativos a la comercialización.

\section{a) Programa de pagos directos}

Bajo este nuevo programa los productores agrícolas reciben subsidios directos del gobierno. El programa de pagos directos reemplaza al programa de contratos flexibles de producción ${ }^{6}$ más conocidos como pagos AmTA (Agricultural Market Transition Act), que existía bajo la Ley Agrícola 1996. Los pagos AMTA se encontraban disponibles para productores de trigo, maíz, cebada, sorgo, avena, algodón y arroz. La Ley Agrícola 2002 incluye pagos directos a esos produc-

\footnotetext{
${ }^{4}$ Véase más detalles sobre los pagos LDP en la sección II, apartado 1d). ${ }^{5}$ La denominación "otras oleaginosas" incluye semillas de girasol, de canola, de mostaza o cualquier otra que determine el Secretario de Agricultura de los Estados Unidos.

${ }^{6}$ Production Flexibility Contracts (PFC).
}

tos, e incorpora además el maní, la soja y otras oleaginosas.

Para recibir asistencia relativa a las cosechas cubiertas por el programa de pagos directos los productores suscriben acuerdos anuales para el período 20022007. El monto que reciben se calcula mediante una fórmula que considera: una tasa de pago (subsidio) por unidad que se otorga para cada cosecha; el $85 \%$ de la superficie de cosecha inscrita por el productor, y un rendimiento preestablecido por cosecha para cada establecimiento agrícola o granja. Así, pago directo $=($ tasa de pago del producto) x (área de cosecha x 0,85 ) x (rendimiento preestablecido).

Al incorporarse a estos programas los agricultores deben elegir entre dos tipos de modalidades para determinar la superficie de cosecha. Lo novedoso de este sistema es que antes de aprobarse la Ley Agrícola 2002 los productores recibían pagos directos que se calculaban sobre la base de la superficie sembrada a mediados de la década de 1990 y de los rendimientos obtenidos en la década de 1980. La Ley Agrícola 2002 permite actualizar las superficies para calcular los pagos directos, utilizando las correspondientes al período 1998-2001. Esta actualización obviamente va a elevar en forma importante los costos presupuestarios.

Los productores tienen casi total libertad para elegir los productos que desean cultivar, a excepción

\begin{tabular}{lcc} 
CUADRO 1 & $\begin{array}{c}\text { Estados Unidos: Tasa para los pagos } \\
\text { directos }\end{array}$ & \\
\hline Producto & Unidad & $\begin{array}{c}\text { Tasa de pago } \\
\text { (en dólares) }\end{array}$ \\
\hline Trigo & Bushel & 0,52 \\
Maíz & Bushel & 0,28 \\
Sorgo & Bushel & 0,35 \\
Cebada & Bushel & 0,24 \\
Avena & Bushel & 0,024 \\
Algodón de altura & Libras & 0,0667 \\
Arroz & Quintal & 2,35 \\
Soja & Bushel & 0,44 \\
Otras oleaginosas & Libras & 0,008 \\
Maní & Tonelada & 36,00
\end{tabular}

Fuente: Departamento de Agricultura de los Estados Unidos. 
de algunas limitaciones en la plantación de frutas y hortalizas. A su vez, deben mantener las tierras dedicadas a "actividades agrícolas" (cultivar, cosechar, pastoreo, prevención de la erosión de los suelos, etc.), y deben respetar disposiciones relacionadas con la conservación de los suelos y del medio ambiente.

Una diferencia importante entre la Ley Agrícola 2002 y la Ley Agrícola 1996 es que esta última establecía montos máximos anuales de pagos directos mientras que la ley nueva no lo hace. Los pagos directos disminuyeron de 5.570 millones de dólares en 1996 a 4.000 millones de dólares en 2002. Cerca del $85 \%$ de esos montos anuales se repartía entre el trigo (26\%), el maíz (46\%) y el algodón (12\%). La Ley Agrícola 2002, en cambio, establece montos específicos por unidad de producto. En consecuencia, ahora no existe un monto máximo establecido para la ayuda total anual, sino que el monto depende de la cantidad producida. ${ }^{7}$ Estos pagos directos aseguran al productor de determinados bienes entre un $10 \%$ y un $20 \%$, en promedio, de ingresos adicionales a los correspondientes a los precios de mercado.

Otra diferencia fundamental entre ambas leyes es que bajo la Ley Agrícola 1996 los pagos AMTA eran definidos sólo para la producción correspondiente a los años base, y las tasas de cálculo se encontraban fijas para cada cultivo. La Ley Agrícola 2002 permite actualizar la superficie base susceptible de acogerse al programa, mediante la incorporación de un promedio de cuatro años (1998 a 2001) de la superficie sembrada. En definitiva, a diferencia de los pagos AMTA, los nuevos subsidios otorgados por el programa de pagos directos no decrecen con el tiempo, son superiores a los pagos vigentes con anterioridad y están vinculados a la superficie cultivada.

\section{b) Programa de pagos contracíclicos (o contraes- tacionales)}

Este nuevo programa fue diseñado para ofrecer a los productores una mejor red de seguridad en materia de ingresos. Busca sustituir los pagos de emergencia autorizados por el Congreso desde 1998 hasta 2001, que en total oscilaron entre 2.900 y 5.500 millones de dólares por año. Los pagos contracíclicos son otorgados cada vez que el precio efectivo de los productos es menor que un precio meta preestablecido por el gobierno.

\footnotetext{
7 Véase Departamento de Agricultura de los Estados Unidos, www.usda.gov.
}

El precio efectivo se calcula con la siguiente fórmula:

donde:

$$
\text { Precio efectivo }=(1)+(2)
$$

(1) es la cifra mayor que resulte de la comparación de $a$ y $b$ :

$a$ es el precio promedio de los últimos 12 meses;

$b$ es la tasa media nacional de préstamo por producto para los créditos de asistencia a la comercialización, y (2) es la tasa establecida para los pagos directos (cuadro 1).

El precio meta es el precio por bushel o por libra al cual el gobierno presta fondos a los productores que participan en los programas de apoyo. Los agricultores pueden obtener un préstamo para toda - o partede su nueva cosecha en cualquier momento posterior a ella hasta el siguiente mes de marzo o mayo, según el cultivo.

La Ley Agrícola 1996 establecía, para la mayoría de los productos incluidos en el programa de asistencia, que las tasas de préstamo debían ser equivalentes a por lo menos el $85 \%$ del precio medio de los últimos cinco años, con precios máximos para algunos productos (Basco, 2002). La Ley Agrícola 2002 fija las tasas de préstamo para 2002-2003 y 2004-2007, siendo las de este último período ligeramente inferiores. Para los productos incluidos (a excepción de la soja), las nuevas tasas son superiores a los máximos autorizados en la legislación anterior. Los cambios más significativos en este instrumento de política corresponden al establecimiento de tasas fijas de préstamos en lugar de tasas variables en función de los promedios de precios de años anteriores.

Los pagos contracíclicos surgen de comparar el mayor precio efectivo (calculado según alguna de las dos formas descritas) con el precio meta determinado

CUADRO 2

Estados Unidos: Precios meta (dólares)

\begin{tabular}{llcc}
\hline Producto & Unidad & 2002-03 & 2004-07 \\
\hline Trigo & Bushel & 3,86 & 3,92 \\
Maíz & Bushel & 2,60 & 2,63 \\
Sorgo & Bushel & 2,54 & 2,57 \\
Cebada & Bushel & 3,21 & 2,24 \\
Avena & Bushel & 1,40 & 1,44 \\
Algodón de altura & Libras & 0,724 & 0,724 \\
Arroz & Quintal & 10,50 & 10,50 \\
Soja & Bushel & 5,80 & 5,80 \\
Otras oleaginosas & Libras & 0,098 & 0,101 \\
Maní & Tonelada & 495,00 & 495,00 \\
\hline
\end{tabular}

Fuente: Departamento de Agricultura de los Estados Unidos. 
por el gobierno. Una vez realizada la comparación para establecer si se debe o no otorgar un pago a los productores, el monto de los pagos contracíclicos se calcula de manera similar a los pagos directos. Se toma en cuenta el $85 \%$ de la superficie de cosecha inscrita por el productor, el rendimiento por cosecha de cada establecimiento agrícola o granja y una tasa de pago contracíclico. La superficie de cosecha se calcula mediante las mismas dos modalidades utilizadas para los pagos directos; a su vez, el rendimiento por cosecha puede ser actualizado en tres formas distintas, incluyendo la actualización de los rendimientos susceptibles de incluirse hasta el $93,5 \%$ de los correspondientes al período 1998-2001. La fórmula resultante es la siguiente:

Pago contracíclico $=($ tasa de pago contracíclico $) \mathrm{x}$ (superficie de cosecha $\mathrm{x} 0,85$ )

$\mathrm{x}$ (rendimiento preestablecido)

donde la tasa de pago contracíclico $=($ precio meta $)$ - (tasa de pago) — (la cifra mayor entre $a$, el precio medio de los últimos 12 meses, y $b$, la tasa de préstamo).

Los precios meta constituyen verdaderos precios de sostén en la medida en que aseguran al productor un ingreso mínimo independiente de las fluctuaciones de los precios de mercado. Esta nueva política aísla casi completamente a los productores estadounidenses de las señales del mercado y constituye un retroceso de la política agrícola de los Estados Unidos con respecto al proceso de liberalización que el gobierno había iniciado. Dada la importancia del aumento de los rendimientos observado en los últimos años, especialmente para algunos productos, estos pagos aumentarán más que proporcionalmente.

\section{c) Préstamos de asistencia para la comercialización y pagos en reemplazo de estos préstamos \\ El gobierno de los Estados Unidos otorga una} serie de préstamos no prorrogables a los productores agrícolas, que deben ser devueltos al cabo de nueve meses. La Ley Agrícola 2002 da continuidad a estos programas, amplía la diversidad de productos cubiertos y elimina el requisito de haber suscrito un acuerdo anual de pagos directos para recibir el préstamo. Los préstamos otorgados a los productores de productos básicos pueden ser pagados de tres maneras: i) devolviendo el préstamo a una tasa determinada y pagando además los intereses establecidos por la Corporación de Crédito para Productos Básicos (CCC); ii) transfiriendo al gobierno su producción, o iii) pagando el préstamo a una tasa alternativa.

Los préstamos de asistencia a la comercialización permiten a los productores pagar los préstamos no prorrogables de apoyo a los productos básicos a una tasa inferior a la inicial, siempre que los precios mundiales del producto en cuestión sean inferiores a la tasa de pago inicial más intereses; con esto se busca evitar que el gobierno se enfrente a una excesiva acumulación de inventarios.

Cuando los precios mundiales del producto básico en cuestión son inferiores a la tasa de pago inicial más intereses de los préstamos no prorrogables concedidos, los productores agrícolas pueden recurrir a una alternativa: el Secretario de Agricultura tiene la facultad de efectuar a discreción pagos directos a productores agrícolas que hayan acordado abstenerse de pedir préstamos no prorrogables en apoyo de productos básicos. Esos pagos (conocidos como LDP) se determinan multiplicando la tasa de pago del préstamo de comercialización por la cantidad del producto básico que puede ser considerado para el préstamo. De esta manera, el agricultor no asume el riesgo de tomar un préstamo de comercialización. Los LDP son contracíclicos por su propia naturaleza, puesto que se paga más por concepto de subsidio a los precios cuando estos son más bajos, y menos cuando son más altos.

Los préstamos de asistencia para la comercialización y los LDP están destinados a reducir al mínimo los potenciales deudores morosos e impedir que el gobierno tenga que acumular inventarios de productos básicos. La Ley Agrícola 2002 agrega el maní, la lana, el mohair, la miel, los garbanzos, las lentejas y las arvejas a los productos elegibles para este tipo de préstamo (que son trigo, maíz, sorgo, algodón, arroz, cebada, soja y otras oleaginosas).

\section{d) Programas de apoyo por sectores y productos}

En este apartado se describen diversas medidas de ayuda para los productores de lácteos, maní, azúcar, lana, angora, miel, garbanzos, lentejas, manzanas, frutas y hortalizas.

i) Productos lácteos. La Ley Agrícola 2002 extiende la implementación del programa de compras gubernamentales y el programa de incentivos a la exportación de productos lácteos, desarticula el programa NorthEast Dairy Compact (de trato especial a la región de Nueva Inglaterra) y establece un nuevo programa de pagos por pérdidas de comercialización de productos básicos (Dairy Market Loss Payments) en reemplazo de los pagos de emergencia autorizados por el Congreso (Market Loss Assistance) y suministrados a los productores de lácteos en 1999, 2000 y 2001.

El programa de compras gubernamentales autoriza a la corporación de créditos para productos básicos 
(Commodity Credit Corporation - CCC) a comprar manteca, leche en polvo descremada y queso a un precio mínimo preestablecido. La Ley Agrícola 1996 establecía precios que irían decreciendo desde 1996 hasta 1999, cuando debían ser eliminados. La promesa de eliminación no se cumplió y los precios preestablecidos fueron extendidos hasta el 31 de mayo de 2002. La Ley Agrícola 2002 mantiene estos precios, los fija al nivel establecido en 1999 y no prevé disminución alguna hasta 2007.

En virtud del programa de compensación por pérdidas de comercialización de productos lácteos ya mencionado, los productores reciben pagos directos en forma mensual, cada vez que el precio mensual de la leche en general, leche descremada, leche con bajo contenido graso, etc. (productos de Clase 1 según las órdenes federales de comercialización $)^{8}$ es inferior a 16,94 dólares por quintal. Los pagos son otorgados hasta un máximo de 2,4 millones de libras de leche por año por organización y el número de productores beneficiados por estas operaciones no afecta los alcances de esta limitación.

El programa de incentivos a la exportación de productos lácteos (que figura entre los programas de apoyo a las exportaciones que se analizan más adelante) subsidia la exportación de productos lácteos estadounidenses con pagos, basados en licitaciones, a las empresas que venden productos lácteos para la exportación. Dispone expresamente que el Secretario de Agricultura deberá autorizar subsidios suficientes como para exportar los máximos volúmenes de productos lácteos permitidos por los compromisos contraídos en la Ronda Uruguay del GATT. Este programa se utiliza con la finalidad de desarrollar mercados y fue extendido hasta 2007 por la Ley Agrícola 2002.

ii) Maní. El programa de sostén del precio del maní se elimina y es reemplazado por un sistema de pagos directos, pagos contracíclicos y préstamos para la comercialización, similar a los programas para el resto de los productos básicos. Se elimina la cuota de comercialización interna de maní vigente bajo la Ley Agrícola 1996 y los tenedores de esta cuota son compensados a través de un sistema de recompra de cuotas. Con este nuevo sistema se equiparan las posibili-

\footnotetext{
${ }^{8}$ Las órdenes federales de comercialización de productos lácteos fueron diseñadas para ayudar a establecer y mantener condiciones ordenadas y claras de comercialización. Estas disposiciones establecen un sistema de precios donde se clasifican y fijan precios según los productos para los cuales se emplea la leche. La Clase 1 mencionada pertenece al primer escalón de una clasificación de 11 categorías.
}

dades de acceso de los productores de maní a los programas de apoyo del gobierno.

iii) Azúcar. Antes de 1996, el programa azucarero debía ser administrado con costo neto cero. La condición de costo neto cero significaba que la cCC tenía prohibido acumular azúcar adquirida en virtud de los programas de asistencia a productos básicos. Este mandato se cumplía ajustando los contingentes de importación o usando cuotas de comercialización internas. La Ley Agrícola 1996 no incluyó la condición de costo neto cero y la autoridad para asignar cuotas de comercialización no fue renovada. La Ley Agrícola 2002, por su parte, restablece el mecanismo, para evitar la derivación al gobierno de existencias correspondientes a los programas de préstamos no prorrogables; autoriza hasta 2007 el programa de préstamos no prorrogables (18 centavos de dólar por libra de azúcar de caña sin refinar y 22,9 centavos de dólar por libra de azúcar de remolacha refinada), y suspende los pagos por comercialización de azúcar, junto con las penalidades por derivación del producto.

Asimismo, la Ley Agrícola 2002 reintroduce un sistema de control de la oferta que había sido eliminado en la Ley Agrícola 1996: el Secretario de Agricultura queda autorizado para establecer cuotas de mercado con el fin de equilibrar la oferta y la demanda, evitar derivaciones de productos a las existencias del gobierno y cumplir con los compromisos de importación de azúcar. La nueva ley crea también el programa de préstamos para facilitar el almacenaje de azúcar, que brinda a los procesadores de azúcar de caña y de remolacha financiamiento para construir o mejorar las instalaciones de almacenamiento.

El programa de pagos en especie (РIK) continúa. Este programa ofrece a los productores de azúcar de remolacha la opción de cambiar una parte de su cosecha por azúcar que la CCC mantiene en inventario.

Se mantiene la cuota de importación de azúcar, que limita las importaciones de este producto con el fin de mantener su precio interno. La cuota alcanza a 1,23 millones de toneladas de azúcar de caña en bruto y 24.250 toneladas de azúcar refinada.

iv) Lana, angora, miel, garbanzos y lentejas. Estos productos, que no recibían apoyo bajo la Ley Agrícola 1996 (excepto a través de pagos ad hoc), tienen en virtud de la Ley Agrícola 2002 un nivel garantizado de apoyo a través de préstamos de asistencia para la comercialización y de pagos LDP. De esta manera se amplía la cantidad de productos que reciben apoyo directo del gobierno, estableciendo la posibilidad de incorporar nuevos productos en el futuro próximo. 
v) Manzanas, frutas y hortalizas. La Ley Agrícola 2002 incluye 100 millones de dólares de subsidios para los productores de manzanas, supuestamente en compensación por los bajos precios del año 2000, y más de 200 millones de dólares de fondos adicionales para comprar y distribuir frutas y hortalizas a través de varios programas.

\section{e) Límites máximos de los pagos en virtud de los programas de productos básicos}

Para los pagos directos, los máximos se mantienen en 40.000 dólares por persona. Para los pagos contracíclicos, el límite establecido alcanza a 65.000 dólares. Los correspondientes a los préstamos de comercialización llegan a 75.000 dólares. Los productores con ingresos brutos medios por encima de 2,5 millones de dólares durante tres años sólo tendrán derecho a pagos si el $75 \%$ de esos ingresos proviene de la agricultura.

La Ley Agrícola 2002 da continuidad a la regla de la triple entidad, bajo la cual un agricultor individual que posee tres granjas o establecimientos agrícolas puede recibir un pago directo anual completo por su primera granja y la mitad del pago por cada una de las granjas restantes. Es decir, recibe hasta el doble del pago anual total en calidad de pagos por contrato y por ganancias de préstamos de comercialización correspondientes a tres granjas separadas (un pago completo por la primera operación y hasta la mitad del pago por cada una de las dos restantes).

A pesar de que la Ley Agrícola 2002 contiene medidas para limitar los subsidios bajo programas específicos a un total de 360.000 dólares por establecimiento agrícola o granja, una serie de excepciones contenidas en la ley puede llegar a anular este límite. Por ejemplo, en virtud del certificado de préstamo de cosecha (crop loan certificate), los agricultores que tomaron préstamos no prorrogables por los montos más altos y debieron entregar sus cosechas en pago pueden comprar estos certificados a la CCC a una tasa inferior a la tasa inicial más intereses del préstamo al cual se comprometieron, y luego cambiarlos por las cosechas entregadas en garantía. De este modo, los grandes productores recuperan sus cosechas y pagan los préstamos a una tasa inferior. Con estas disposiciones, la gran cantidad de pagos establecidos por la Ley Agrícola 2002 va a beneficiar a los grandes productores, y no a los pequeños granjeros, a quienes supuestamente está dirigida esta normativa. f) Costo de los subsidios a los productos básicos

Las primeras estimaciones indican que los costos de los subsidios directos y de los pagos contracíclicos se encontrarían entre los 11.000 y 12.000 millones de dólares anuales. Los pagos realizados bajo el programa de préstamos en 1999-2001 han estado entre los 6.000 y 8.000 millones de dólares, y si los precios mantuviesen sus niveles los gastos serían similares en los próximos años. Sin embargo, se estima que el monto de los pagos va a aumentar, por cuanto la Ley Agrícola 2002 acentuará el descenso de los precios de los productos afectados.

Así, el gasto anual en productos básicos alcanzará, según se estima, a entre 15.000 y 20.000 millones de dólares por año sólo para los cultivos. Esto representa un aumento de 70\% - aunque otras estimaciones preliminares mencionan hasta $80 \%$ - respecto de lo estipulado por la Ley Agrícola 1996 en su último año de vigencia (Unión Europea, 2002).

\section{Programas de conservación}

Los programas de conservación de tierras y recursos naturales existen desde el decenio de 1930 y tienen una gran importancia en la política agrícola de los Estados Unidos. Además de contribuir a promover valores ambientales, los pagos relacionados con la conservación de los recursos naturales pueden constituirse en medidas de apoyo a la producción agrícola.

La Ley Agrícola 1996 contemplaba una serie de programas de conservación, entre ellos el programa de reserva para la conservación (CRP), el programa de reserva de humedales (WRP) y el programa de incentivos para la calidad ambiental (EQIP). En el capítulo sobre conservación, la Ley Agrícola 2002 mantiene los programas anteriores y crea uno nuevo, el programa de seguridad de la conservación (CSP), que ofrece incentivos a los productores para que adopten o mantengan una gama de prácticas estructurales de gestión focalizadas en uno o varios recursos de interés, como los suelos, el agua y la vida silvestre. Dicho capítulo incrementa en $80 \%$ los fondos que ya estaban asignados a los programas ambientales y de conservación, que en conjunto alcanzan a 17.100 millones de dólares.

El programa de reserva para la conservación se traduce en pagos anuales del gobierno y en un sistema de costos compartidos. Los dueños de las tierras agrícolas firman contratos por 10 a 15 años en los que se comprometen a retirar tierra cultivable de la producción y establecer una cobertura de largo plazo del suelo (por ejemplo, árboles o pasto) a cambio de pagos 
anuales. Cuando este programa se inició, su principal objetivo era reducir la erosión. Pero la Ley Agrícola de 1990 amplió los objetivos ambientales del programa a la calidad del agua y la vida silvestre. Durante la década de 1990 sus desembolsos anuales fueron en promedio de 1.500 millones de dólares. Las tierras incluidas fluctuaron entre 30 y 36 millones de acres, con un límite máximo de 36,4 millones de acres, que representan alrededor de un octavo de la tierra que puede ser utilizada para el cultivo de productos básicos. La Ley Agrícola de 2002 aumentó la cobertura máxima de este programa a 39,2 millones de acres y cambió los criterios para acogerse a él.

El programa de reserva de humedales (WRP) se basa en un sistema de compras por el Estado y de costos compartidos y facilidades de pago como incentivos para la incorporación de los productores al programa. La Ley Agrícola 1996 autorizó el pago de 1.300 millones en un período de siete años para ayudar a los agricultores y ganaderos a realizar mejoras ambientales y de conservación en sus propiedades; la superficie máxima cubierta por el programa alcanzó a 1.075 millones de acres. La Ley Agrícola 2002 la amplía a 2.275 millones de acres, con una inscripción máxima anual de 250.000 acres.

El programa de incentivos para la calidad del ambiente (EQIP) ofrece asistencia técnica, costos compartidos e incentivos monetarios para ayudar a los agricultores y ganaderos a adoptar y poner en práctica mejoras ambientales y de conservación en sus establecimientos. La Ley Agrícola 1996 autorizaba hasta 1.300 millones para los siete años del período de implementación. La Ley Agrícola 2002 aumenta significativamente los montos de este programa, pues prevé un incremento progresivo de 400 a 1.300 millones de dólares para el período 2002-2007.

\section{Programas de apoyo a las exportaciones}

Es frecuente que los productos de los países de América Latina deban competir con mercancías estadounidenses, tanto en el mercado interno como en otros mercados de exportación. Los programas de apoyo de los Estados Unidos a sus propias exportaciones facilitan las operaciones de exportación de ese país en el extranjero mediante incentivos especiales y facilidades de crédito a los posibles compradores, e infraestructura en el exterior para el almacenamiento de productos agrícolas estadounidenses. El gobierno de los Estados Unidos opera varios programas de asistencia a las exportaciones: el programa de fomento de las expor- taciones, el programa de incentivos a las exportaciones de productos lácteos, el programa de acceso a los mercados, el programa de desarrollo de mercados externos y el programa de mercados emergentes. A su vez, el Departamento de Agricultura de los Estados Unidos maneja cuatro programas de garantías para los créditos de exportación: i) el programa de garantías de créditos de exportación de corto plazo (GSM-102), que es el programa de fomento de las exportaciones de mayor envergadura de los Estados Unidos y está administrado por la CCC; ii) el programa de garantías para créditos de exportación de mediano plazo (GSM-103); iii) el programa de garantías de créditos a los proveedores, y iv) el programa de garantías de créditos para infraestructura. Las disposiciones de la Ley Agrícola 2002 inciden en los diversos programas estadounidenses de asistencia para la exportación de las siguientes maneras:

- La Ley Agrícola 1996 asignaba un monto mínimo anual de 5.500 millones de dólares a los programas GSM-102 y GSM-103 y fijaba la proporción de las garantías de créditos que debía destinarse como mínimo a productos procesados de alto valor: 25\% en 1996 y 1997, 30\% en 1998 y 1999, y 35\% de ahí en adelante. La Ley Agrícola 2002 mantiene estas disposiciones, de modo que una fracción no inferior a 35\% de las garantías debe destinarse a dichos productos.

- En el programa de garantía de créditos para proveedores (SCGP), la Ley Agrícola 2002 extiende de 180 a 360 días el plazo para los créditos de corto plazo otorgados en virtud de este programa, con el fin de alentar a los exportadores estadounidenses a que amplíen, mantengan o desarrollen mercados para los productos agrícolas de su país en zonas en que no pueden acceder al financiamiento comercial sin una garantía de la CCC.

- Respecto de los créditos directos o garantías de crédito para las exportaciones a mercados emergentes, la Ley Agrícola 2002 dispuso que se destinen 1.000 millones de dólares a estos programas con miras a proveer instalaciones y servicios o suministrar productos estadounidenses para mejorar las condiciones de transporte, manipulación, comercialización, procesamiento, almacenaje o distribución de productos agrícolas estadounidenses en los mercados identificados.

- Estados Unidos otorga ayuda alimentaria a través del programa Food for Progress (Ley Pública 480). La Ley Agrícola 2002 autoriza la extensión del programa hasta el 2007. A la vez, incluye como objetivo la prevención de conflictos y aumenta los 
niveles mínimos de asistencia de 1.875 millones de toneladas métricas anuales a 2.500 millones, entre otras disposiciones.

- Además de efectuar cambios en los programas existentes, la Ley Agrícola 2002 establece nuevos programas con el fin de eliminar, resolver o mitigar barreras sanitarias y fitosanitarias y otras barreras técnicas al comercio:

- El programa de comercio agrícola y biotecnología se ocupa de las barreras regulatorias no arancelarias a las exportaciones de productos básicos de Estados Unidos. Autoriza donaciones para proyectos del sector público y del sector privado vinculados a temas de biotecnología, inocuidad alimentaria, enfermedades u otros temas sanitarios y fitosanitarios.

- El programa de asistencia técnica para especialidades (TASC) apoya a las exportaciones frente a barreras singulares que prohíben o amenazan las exportaciones de especialidades de Estados Unidos, a través de proyectos del sector público y del sector privado, y asistencia técnica para atender a temas delicados y estra- tégicos de retención de mercados, acceso a mercados y expansión de mercados. El monto destinado a estas tareas alcanza los 19 millones de dólares.

La novedad respecto de los programas de apoyo a las exportaciones en la Ley Agrícola 2002 es la exigencia al Secretario de Agricultura y al Representante de Comercio de Estados Unidos de que realicen consultas regulares con los comités del Senado y de la Cámara de Representantes sobre las negociaciones vinculadas con los programas de garantía a los créditos de exportación de productos agrícolas que se lleven a cabo en el ámbito de la omc y en la Organización para la Cooperación y el Desarrollo Económicos (OCDE). Si hasta ahora no ha sido posible que los Estados Unidos y demás países de la ocDE lleguen a acuerdo sobre disciplinas mínimas para el uso de los créditos de exportación y de los subsidios a las exportaciones otorgados mediante garantías gubernamentales, con este nuevo mecanismo de consulta va a resultar bastante más difícil lograrlo, aunque Estados Unidos presente una oferta ambiciosa en la OMC para desmantelar dichos créditos

\section{III}

\section{La Ley Agrícola 2002 y las disposiciones de la omc}

\section{Las medidas de ayuda a la agricultura y su clasificación por la omc}

El Acuerdo sobre la Agricultura ${ }^{9}$ de la omc clasifica las medidas de ayuda interna a la producción y comercialización de productos agrícolas utilizando tres "compartimientos": las medidas de la "caja ámbar", las medidas de la "caja verde" y las medidas de la "caja azul". Estos compartimientos, que establecen las reglas generales para el uso de los subsidios en la agricultura, son de suma importancia para entender la naturaleza de los nuevos programas incluidos en la Ley Agrícola 2002.

- Las medidas de la caja ámbar son aquellas consideradas distorsionantes del comercio. Incluyen entre otras, los precios de sostén, los pagos direc-

\footnotetext{
9 Véase GATT (1994).
}

tos que afectan el volumen de producción (los llamados "pagos conectados") y los subsidios a los insumos y al capital. Estas medidas están sujetas a reducciones progresivas y a revisiones periódicas, y son las que se toman en cuenta para calcular la Medida Global de la Ayuda (MGA).

- Las medidas de la caja verde son las que no implican pagos directos a los productores, tienen efecto nulo o mínimo sobre la producción y el comercio, no incrementan los precios de mercado y deben estar financiadas por el presupuesto público. Estas medidas se identifican como "pagos desconectados" y están exentas del compromiso de reducción.

- Las medidas de la caja azul son pagos directos que se efectúan en el marco de programas para limitar la producción que se basan en superficies y rendimientos fijos, se aplican al $85 \%$ o menos del 
nivel de producción base y, en el caso de pagos relativos a ganado, se realizan respecto a un número fijo de cabezas. Estos pagos están exentos de los compromisos de reducción correspondientes a la MGA.

- La cláusula de minimis constituye una excepción a las reducciones de la caja ámbar. Establece que las subvenciones de pequeña escala están exentas de reducción o eliminación. La ayuda a productos específicos no debe exceder el $5 \%$ del valor total de la producción del bien en el caso de los países desarrollados y el $10 \%$ en el caso de los países en desarrollo. La ayuda interna no referida a productos específicos no debe superar el 5\% del valor de la producción agropecuaria total en el caso de los países desarrollados, ni el $10 \%$ en el caso de los países en desarrollo.

Una condición clave en la clasificación de los susbsidios es el carácter de desconectados de los pagos a los productores, es decir, su calidad de independientes de la producción, de los precios internos y externos y del uso de insumos. En la medida en que estos pagos se encuentran predeterminados y no varían con los cambios en la producción y en las condiciones de mercado, se rompe la relación entre sostén y producción. Dicho de otro modo, la producción será casi la misma con estos pagos o sin ellos. En consecuencia, se dice que estos pagos desconectados son "mínimamente distorsionantes".

La fundamentación de los pagos desconectados y sus efectos poco distorsionantes se encuentra en el hecho de que la libertad de sembrar y de elegir entre cultivos año a año permite reducir las distorsiones correspondientes al pago de subsidios con base en un cultivo en especial. Si todos los apoyos a la agricultura fueran de carácter desconectado, los agricultores responderían a los cambios marginales de los precios en los mercados mundiales y de esa manera producirían lo mismo que si no hubiera intervención en los mercados. En la medida en que los pagos no estén relacionados con ninguna de las variables principales que influyen sobre las decisiones de producción, los agricultores invertirán su dinero en las actividades que les ofrezcan las ganancias más elevadas. Pero lo más importante para evaluar si los llamados pagos desconectados distorsionan o no el mercado, es dilucidar si esas ayudas incentivan a los agricultores a sembrar una mayor superficie o a producir más con el objeto de recibir en el futuro mayores beneficios del gobierno.

Dependiendo de si cumplen o no con la condición de pago desconectado, se determina la clasificación de los subsidios en los distintos compartimientos, así como los respectivos regímenes que deben seguir. Si los pagos se encuentran conectados a alguna variable vinculada al volumen de producción y no cumplen con las disposiciones de la "caja azul", se clasifican en la "caja ámbar" y, por ende, se encuentran sujetos a los límites establecidos por la Medida Global de la Ayuda y a compromisos de reducción. Por el contrario, si los pagos conectados cumplen con las disposiciones de la "caja azul", se clasifican como excepciones y quedan exentos de los compromisos de reducción. En el caso de que los pagos sean desconectados, se clasifican dentro de la "caja verde" y no están sujetos a las límitaciones de la MGA ni a compromisos de reducción.

\section{Clasificación de los programas de pagos di- rectos}

Los pagos directos deberían clasificarse en la caja ámbar en calidad de conectados y ser contabilizados dentro de los compromisos de la Medida Global de la Ayuda, es decir, dentro del límite máximo de gasto anual en apoyo a la agricultura que Estados Unidos se ha comprometido en la OMC a respetar.

En 1996 los llamados pagos LDP fueron sustituidos por los pagos desconectados establecidos por la AMTA. Esto pareció ser un principio de compromiso de los Estados Unidos de intentar despegarse del carácter intensamente conectado de los tradicionales programas de apoyo a los ingresos agrícolas que se habían establecido a partir de la década de 1930. Cuando los pagos AMTA fueron introducidos en 1996, parecían otorgarse de manera bastante ajustada a los exigencias impuestas a los pagos desconectados. Se hacían efectivos sobre la base de superficies y rendimientos fijos correspondientes a promedios anteriores a 1996; no variaban con los cambios en la producción, los precios o el uso de insumos, y los agricultores tampoco tenían que haber cosechado previamente algún cultivo para poder recibirlos. Y los Estados Unidos los notificó a la OMC como pagos desconectados.

Hasta 2001, los pagos caracterizados como desconectados se habían ajustado a criterios claramente definidos, con base en superficies y rendimientos anteriores a 1996. La Ley Agrícola 2002, en cambio, ofrece a los agricultores la opción de actualizar esas superficies y rendimientos a los promedios correspondientes a los años 1998-2001. Por lo tanto, aquellos agricultores que plantaron más y/o cultivaron más intensivamente su tierra a partir de 1996 con la expectativa de que sus 
cabilderos pudieran convencer al Congreso de actualizar sus bases de pago futuras y así aumentar el monto de sus futuros pagos, consiguieron elevar de manera permanente sus ingresos provenientes de pagos desconectados.

\section{Clasificación de los programas de pagos contracíclicos}

Los subsidios relacionados con los precios de los productos deben quedar en la caja ámbar, según lo establecido en el Acuerdo sobre la Agricultura de la OMC, y ser contabilizados dentro de los límites máximos comprometidos en esa organización. Sin embargo, los propulsores de la Ley Agrícola 2002 sostienen que los subsidios contracíclicos no deben ser contabilizados contra el límite máximo comprometido, sino dentro de los subsidios de minimis permitidos. También sostienen que se trata de subsidios no específicos.

Sin embargo, la cláusula de minimis permite que aquellos subsidios que no excedan el 5\% del valor de la producción de cada cultivo incluido en los pagos queden exceptuados del cálculo de la MGA. Para los pagos que no son específicos a un determinado producto, la exención se basa en el valor total de la producción agrícola. Dado el alto valor de la producción agrícola estadounidense (alrededor de 190.000 millones de dólares anuales), el 5\% de ella (alrededor de 10.000 millones de dólares) permitiría cubrir cualquier tipo de subsidio. Además, la Ley Agrícola 2002 establece que los pagos contracíclicos se determinen por lo cultivado en el año base, por lo cual reflejarán los movimientos de precios de cada cultivo contemplado. Claramente, se trata de pagos vinculados a productos específicos y no pueden contabilizarse como no específicos.

Por otra parte, la aprobación de paquetes de ayuda de emergencia a partir de 1998 y hasta 2001 aumentó a medida que descendían los precios. Estos pagos fueron distribuidos entre los agricultores utilizando como base las mismas superficies y rendimientos que se empleaban para los pagos AmTA. Después de varias demoras en la presentación de las notificaciones correspondientes, y dado que se discutió mucho a nivel de gobierno, sectores académicos y organizaciones de productores, el gobierno estadounidense comenzó a notificar a la OMC estos pagos adicionales como incluidos en su Medida Global de la Ayuda (MGA), que está compuesta por medidas de ayuda internas consideradas distorsionantes del mercado y sometidas a las reducciones acordadas.

\section{4. ¿Constituye la Ley Agrícola de 2002 una vio- lación a los compromisos acordados en la Me- dida Global de la Ayuda?}

El tema de la clasificación de los distintos programas de apoyo no es menor, ya que de su resultado depende la conformidad de la Ley Agrícola 2002 con los límites comprometidos por los Estados Unidos en la MGA. La MGA es el nivel de ayuda anual, expresado en términos monetarios, que se otorga a un producto agropecuario, $\mathrm{o}$ a los productores del producto agropecuario base, o el nivel de ayuda no referida a productos específicos otorgada a los productores agrícolas en general. La MGA se aplica a todas las medidas de apoyo internas, salvo las incluidas en la caja verde y la caja azul y en la cláusula de minimis.

Lo más importante es saber qué va a pasar con el compromiso asumido por Estados Unidos respecto al límite de 19.100 millones de dólares por año de la MGA establecido oportunamente en la Ronda Uruguay. El presupuesto total de la Ley Agrícola 2002 ha sido estimado en 180.000 millones de dólares para el período de implementación (Unión Europea, 2002). Por la diferencia obvia entre el monto consolidado como techo en la OMC y el que se prevé desembolsar, parece probable que los desembolsos superen el límite consolidado en la MGA. Sin embargo, por algunas declaraciones del Departamento de Agricultura de los Estados Unidos, también parece probable una discusión ardua de cómo debe ser clasificado cada gasto para determinar si debe o no computarse en la MGA.

Para evitar problemas, la Ley Agrícola 2002 autoriza al Secretario de Agricultura a realizar ajustes hasta el "máximo grado factible" para asegurar que no se excedan los compromisos contraídos en la OMC. Una posibilidad extrema frente a un caso de exceso de desembolso es la exigencia de que los agricultores devuelvan la proporción de los pagos recibidos que excedieron el límite, tema que plantea problemas operativos, además de dificultades políticas debidas a las fuertes resistencias de los productores. Otra posibilidad es que simplemente se opte por no cumplir con lo comprometido, y enfrentar reclamos de el o los países afectados, situación que puede dirimirse a través del sistema de solución de controversias, o bien que se recurra a ofrecer compensaciones u otras alternativas innovadoras para reclasificar los subsidios. Una tercera posibilidad es la de que Estados Unidos no esté muy preocupado por los efectos a largo plazo, y que la Ley Agrícola de 2002 constituya justamente un elemento estratégico de negociación que apunte a alterar 
los compromisos asumidos y cambiar las reglas de juego en las negociaciones en curso de la OMC.

Ante la interrogante de si la Ley Agrícola 2002 representa una violación a las reglas convenidas en el marco de la OMC, las opiniones se encuentran divididas. Hasta la fecha no ha habido una presentación formal en la OMC que cuestione la legalidad de esta nueva ley, aunque muchas delegaciones, incluyendo las de Brasil,
Colombia, Paraguay y Uruguay, han expresado preocupación por su contenido, y algunos gobiernos (el de Brasil, por ejemplo) han anunciado a los medios de prensa su voluntad de iniciar consultas en el marco de la OMC (primer paso para un cuestionamiento en el marco del sistema de solución de disputas). Sin embargo, esta cuestión sólo se podrá zanjar en el largo plazo, con los resultado anuales del cálculo de la MGA.

\section{IV}

\section{El impacto de la Ley Agrícola 2002 sobre la agricultura de los países de América Latina}

La Ley Agrícola 2002 de los Estados Unidos es una normativa compleja, por lo que es difícil evaluar cabalmente el impacto económico y comercial que ha de tener. Aun así, se puede realizar una primera aproximación a sus posibles implicancias para la agricultura de los países latinoamericanos.

\section{Efectos de algunos programas de apoyo}

Las exportaciones agrícolas de los Estados Unidos representan el $25 \%$ de su producción agrícola, cifra que se eleva hasta el $40 \%$ para algunos cultivos, como el trigo. Los pagos LDP y los pagos contracíclicos van a hacer que las exportaciones estadounidenses de los productos que los perciben se abaraten y lleguen subsidiadas a los mercados mundiales.

Los pagos contracíclicos y los pagos LDP garantizan a los granjeros estadounidenses un determinado nivel de ingreso. Por lo tanto, hacen que ellos presten menos atención a las señales del mercado, lo que resulta particularmente perjudicial en los períodos de precios deprimidos. Debido a la forma en que funcionan estos mecanismos de pagos, la caída de los precios puede significar que los granjeros obtengan mayores ingresos que los que ganarían si los precios en el mercado fueran más altos. Esto puede crear un desincentivo para frenar la sobreproducción. Dado que el ingreso garantido significa retorno asegurado sobre lo que se coseche, no hay razón alguna para que los granjeros estadounidenses dejen de acrecentar su producción hasta el máximo posible y se despreocupen de si su cosecha va a encontrar un comprador a buen precio. Lo más probable es que la sobreproducción des- borde el mercado y deprima los precios, mientras los ingresos de los granjeros estadounidenses estarán protegidos por los pagos LDP y pagos contracíclicos aún mayores.

El hecho central es que la aplicación de subsidios ocasiona sobreproducción, lo que deprime los precios y conduce a una suerte de dumping de productos básicos en el mercado mundial. Según estimaciones preliminares, la reducción de los precios internacionales ocasionada por la Ley Agrícola 2002 sería del orden del 5\% al 8\% (Gardner, 2002). Este tipo de competencia desleal que genera la Ley Agrícola 2002 implica serias amenazas a los productores agrícolas no sólo de América Latina, sino de todos los países involucrados en actividades agropecuarias.

De hecho, estos programas de apoyo no sólo llevan a producciones ineficientes, sino que también favorecen comportamientos monopólicos. Esto último sucede, por ejemplo, con los productores de granos y algodón. Entre los más de dos millones de productores agrícolas estadounidenses que reciben subsidios del gobierno, el 10\% acapara el 67\% de los 19.000 millones de dólares que se otorgan por año (Clarín, 2002). Según estadísticas estadounidenses (Departamento de Agricultura de los Estados Unidos, 2002), esos grandes agricultores usaron los cheques del gobierno para agrandar sus predios mediante la compra de granjas vecinas y aumentar así su producción. Para ellos el negocio sigue siendo rentable porque la diferencia la pone el gobierno.

Otra consecuencia de la Ley Agrícola 2002 es que, al abaratar los productos básicos en el mercado interno, provee de insumos baratos a la industria 
agroalimentaria. Uno de los casos destacables es el de los productores de ganado vacuno, aves, cerdos y leche, que tienen acceso a forraje más barato y así aumentan su competitividad en mercados externos o desincentivan las importaciones de esos productos desde otros países más eficientes. Esto fuerza a los exportadores marginales a retirarse del mercado, entregándolo muy posiblemente a las exportaciones subsidiadas estadounidenses. Al reducir artificialmente los precios de los productos básicos en el mercado interno, Estados Unidos se vuelve menos atractivo para los potenciales importadores. De esta manera se cierra el círculo de aislamiento de los productores estadounidenses respecto de las señales de los mercados internacionales.

\section{Impacto por sectores y países}

- Los productos de mayor interés de los países de la región —como azúcar, frutas cítricas, jugos de naranja, pomelo y limón, manzanas, hortalizas en general, maní, algodón y tabaco- tienen muy pocas posibilidades de lograr un acceso mayor al mercado estadounidense. Los efectos de la Ley Agrícola 2002 sobre las importaciones y las producciones locales variarán de un país a otro. En el caso del trigo, Estados Unidos aumentará su competitividad frente a Argentina y Canadá en todos los mercados de la región. La nueva ley también parece haber decidido dar batalla a Canadá en el mercado de trigos de alta calidad.

- Los subsidios estadounidenses al maíz y al sorgo afectarán especialmente a los pequeños producto- res locales de los países latinoamericanos, que van a sufrir su impacto y enfrentar dificultades para sobrevivir. Los grandes productores de la región verán reducirse sus ingresos provenientes de las exportaciones y los consumidores locales se beneficiarán por esos menores precios. Los subsidios a la soja afectarán principalmente a Brasil y Argentina, cuyos ingresos de exportación descenderán por los menores precios.

- Las producciones lácteas de todos los países latinoamericanos se verán afectadas negativamente por las nuevas regulaciones estadounidenses. El mantenimiento y profundización de los subsidios internos y a la exportación de productos lácteos deprimirán aún más los precios internacionales. A las producciones menos competitivas de la región les va a ser difícil continuar en la actividad porque los niveles arancelarios necesarios para hacerlo podrían exceder los compromisos globales asumidos en la OMC.

- Las producciones locales de carne aviar se encuentran entre las más afectadas. El abaratamiento de los alimentos, y los subsidios en general, aumentarán la competitividad de las exportaciones estadounidenses de esa carne, lo que presionará para que haya un ajuste de las producciones locales, especialmente en los países que mantienen protección para el maíz y/o el sorgo.

- Las exportaciones de preparados alimenticios estadounidenses, como los preparados de cereales para desayuno, aumentarán su competitividad, desincentivando la producción local.

\section{V}

\section{Consideraciones finales}

La Ley Agrícola 2002 de los Estados Unidos apunta a varios objetivos. Se enmarca en un juego de dos niveles, donde, por un lado, se busca fortalecer la capacidad productiva del sector agrícola estadounidense y responder a las presiones de los tradicionales cabildeos de sus agricultores, y, por otro, se busca cambiar las reglas del juego en el tablero multilateral que rige la agricultura.

A lo largo de este trabajo se detallaron los programas de apoyo comprendidos en esta ley que más pueden afectar a las economías y los mercados de los países de América Latina. A través de un análisis de las disposiciones de la omc relativas a las medidas de apoyo interno y la clasificación de los subsidios, se buscó caracterizar los nuevos programas establecidos en esta normativa. En un intento por calcular el impacto de las nuevas medidas de apoyo a la agricultura estadounidense sobre la actividad agrícola de los países latinoamericanos, se señalaron los efectos de largo plazo que se podrían hacer sentir en los diversos sectores y productos básicos de los países latinoamericanos. 
La Ley Agrícola 2002 aumenta el número de mecanismos de protección y de ayuda al sector agrícola de Estados Unidos, y eleva los montos que había establecido la Ley Agrícola 1996. Es muy probable que aísle a los granjeros/productores agrícolas estadounidenses de las señales del mercado y deprima los precios internacionales de los productos básicos. Con la actualización de la superficie y los rendimientos que sirven de base para determinar los montos de los subsidios, la nueva normativa cambia la naturaleza de los pagos que realiza el gobierno, de "desconectados" a "reconectados". Dadas las características de los mecanismos de apoyo utilizados, los fondos que habrá que desembolsar en virtud de la Ley Agrícola 2002 probablemente superen el límite de la Medida Global de la Ayuda consolidada por Estados Unidos en la OMC.

Algunos acontecimientos recientes han confirmado los temores iniciales sobre la posición estadounidense respecto de las medidas de apoyo a la agricultura y su relación con la Ley Agrícola 2002. En la reciente Conferencia Ministerial de la OMC en Cancún, correspondiente a la Ronda de Negociaciones Comerciales Multilaterales de Doha, las negociaciones comerciales colapsaron debido a la falta de acuerdo en los temas agrícolas.

El camino adoptado por Estados Unidos en la implementación de la Ley Agrícola 2002 definió una posición muy alejada de los discursos oficiales sobre la liberalización del comercio. Incluso parece ir a contramano de las recientes reformas llevadas a cabo por la Unión Europea en su Política Agrícola Común, que apuntaron a la desconexión de los pagos otorgados a los agricultores y a la reducción de las medidas de caja azul, aunque aumentando las medidas de caja verde. Las alianzas surgidas en las negociaciones agrícolas pusieron en evidencia la posición proteccionista de Estados Unidos. A diferencia de lo acontecido en la Ronda Uruguay, donde la puja en agricultura se dio principalmente entre ese país y la Unión Europea por la reducción de los subsidios, en las negociaciones actuales los Estados Unidos y la Unión Europea presentaron una propuesta conjunta de negociación. Dicha propuesta, bastante alejada de la propuesta inicial estadounidense, alertó a los países en desarrollo y obligó a crear una nueva alianza para contrapesar tal posición.

El fracaso de la Conferencia de Cancún plantea serias dudas sobre la posibilidad de completar la Ronda de Doha en 2005, fecha estipulada para la finalización del proceso de negociaciones. Esto puede significar tanto una amenaza como una oportunidad para los países de América Latina; de lo que no cabe duda es que la Ley Agrícola 2002 constituye un elemento estratégico para alterar los compromisos asumidos y cambiar las reglas del juego en las negociaciones en curso en la OMC. En este sentido, lo que más preocupa, además de los cuantiosos montos destinados a subsidios, tiene que ver con la reclasificación de los programas de ayuda en la omc que favorecería la legitimación de los nuevos programas de apoyo estadounidenses.
Basco, C. (2002): Las políticas agrícolas y comerciales de Estados Unidos de América y Canadá, ALADI/SEC/Estudio 148, Secretaría General de la ALADI, Montevideo.

Clarín (2002): Suplemento económico, Buenos Aires, 1 de septiembre. Departamento de Agricultura de los Estados Unidos (2002): http:/ /www.usda.gov/

Gardner, B. (2002): North American Agricultural Policies and Effects on Western Hemisphere Markets since 1995, with a Focus on Grains and Oilseeds, Working Paper, $\mathrm{N}^{\mathrm{o}}$ 12, Maryland, Universidad de Maryland.

GATT (Acuerdo General sobre Aranceles Aduaneros y Comercio) (1994): Acuerdo sobre la agricultura, Acta final en que se incorporan los resultados de la Ronda Uruguay de negociaciones comerciales multilaterales, Ginebra.
Gobierno de los Estados Unidos (1996): Federal Agriculture Improvement and Reform Act of 1996, Washington, D.C., Cámara de Representantes y Senado.

(2002): Farm Security and Rural Investment Act of 2002, Washington, D.C., Cámara de Representantes y Senado.

OCDE (Organización de Cooperación y Desarrollo Económicos) (2001): OCDE en cifras, 2001, París.

OMC (Organización Mundial del Comercio) (1995): GATT/Acuerdo sobre la Agricultura, Marrakesh.

Representante de Comercio de los Estados Unidos (2002): http:// www.ustr.gov/, agosto-octubre.

Unión Europea (2002): Questions \& Answers - US Farm Bill, Memo/XX/XX, Bruselas, http://europa.eu.int. 